\title{
O grau em perspectiva, de José Romerito Silva
}

\author{
Edvaldo Balduino Bispo \\ Professor Adjunto IV da UFRN, edbbispo@gmail.com
}

\section{Resenha do livro:}

SILVA, José Romerito. O grau em perspectiva: uma abordagem centrada no uso. São Paulo: Cortez, 2015, 140p. (Coleção Leituras introdutórias em linguagem, v. 5)

O livro O grau em perspectiva: uma abordagem centrada no uso traz uma discussão detalhada e, ao mesmo tempo, acessível sobre o grau, sendo este tomado não apenas como uma categoria da língua, mas como um domínio funcional ao qual se associam diferentes formas de expressão. Trata-se de uma obra singular e bem-vinda ao meio acadêmico dado o modo como o fenômeno em foco é abordado. $\mathrm{O}$ autor procura aliar, de maneira clara e em linguagem simples, aspectos cognitivos, semânticos e sociopragmáticos, relacionados ao polo da função, a aspectos linguísticos, vinculados ao polo da forma, no tratamento do grau.

Além de apresentar a abordagem das gramáticas tradicionais, a obra discute aspectos funcionais e formais do grau, contemplando, entre outras questões, uma tipologia semântica para essa categoria, projeções metafóricas e/ou metonímicas em noções graduais e variados modos de codificação da noção gradual, os quais incluem os planos fonético, morfológico, lexical, sintático e textual.

Em consonância com a postura teórica que adota, José Romerito Silva baseia sua discussão sobre o grau em dados da língua em uso (de fala e de escrita), os quais provêm, em sua maioria, do corpus Discurso \& Gramática, seções do Rio de Janeiro (RJ), Rio Grande (RS), Niterói (RJ) e Natal (RN). São também utilizados como material de análise o Banco Conversacional de Natal, além de textos oriundos de fontes diversas, a exemplo de livros, jornais, revistas e sites. 
O livro está dividido em quatro capítulos e três seções extras, uma de introdução do tema, outra de desdobramentos da temática e uma terceira destinada a textos comentados sobre o mesmo assunto. $\mathrm{O}$ primeiro capítulo é dedicado à caracterização da perspectiva teórica que fundamenta o exame do grau, a Linguística Funcional Centrada no Uso (LFCU). Os demais capítulos voltam-se à discussão do grau propriamente dita, considerando o tratamento dispensado por manuais de gramática tradicionais, além dos aspectos funcionais e formais dessa categoria.

No primeiro capítulo, Silva define o aparato teórico em que fundamenta o estudo do grau por ele empreendido: a LFCU. Apresenta, de forma sucinta e objetiva, os postulados básicos e conceitos gerais dessa vertente teórica, a qual reúne pressupostos de categorias analíticas da Linguística Funcional norte-americana e da Linguística Cognitiva. Em seguida, são caracterizados princípios, processos e categorias de análise da LFCU utilizados no exame do grau: informatividade e perspectivização, iconicidade, categorização, projeções metafóricas e metonímicas.

O segundo capítulo contempla a abordagem do grau feita por gramáticas tradicionais. $\mathrm{O}$ autor mostra que essa abordagem tem-se restringido a uma breve exposição do que normalmente é entendido por grau, seguida de uma descrição semântico-estrutural. Conforme expõe Silva, essa caracterização envolve a divisão do grau, relacionando-o às categorias de substantivo, adjetivo e advérbio, e uma subdivisão em aumentativo e diminutivo (para o substantivo) e comparativo e superlativo (para adjetivo e advérbio). Esses subtipos podem apresentar-se na forma analítica (por meio de um termo/ elemento graduador) ou de modo sintético (com acréscimo de afixos). É mostrado ainda que a graduação relacionada ao verbo é mencionada apenas por um gramático. Silva destaca, por fim, que o tratamento dado ao grau pela GT é limitado ao viés descritivo e desvinculado das situações reais de uso da língua, além de apresentar, em alguns casos, tendência prescritivista.

O terceiro capítulo volta-se aos aspectos funcionais do grau. Inicialmente, o autor apresenta a definição de grau por ele adotada, confrontando-a com a concepção gramatical clássica. Silva amplia o conceito de grau no sentido de que o toma como uma operação semântico-cognitiva e discursivo-pragmática 
calcada nas experiências humanas individuais (físicas e/ou afetivas) e socioculturais. Na seção seguinte, o autor apresenta uma proposta de tipologia semântica do grau, a qual inclui a seguinte classificação: dimensivo (pedras grandes, cicatriz muito grossa), intensivo (super reservado), quantitativo (pouquinho de sal), hierárquico/posicional (gente de alto nível), avaliativo (Foi um jogão), e afetivo (mainha fica fazendo guerra). Esses tipos podem ocorrer de forma sobreposta.

Também são contempladas pelo autor situações em que a atribuição do grau vem acrescida de outro(s) elemento(s) graduador(es), atuando como reforço/ênfase a uma noção já graduada, como se dá em "...está completamente sem verba e ameaçado de fechar...". Silva destaca que esse reforço está mais associado a questões interacionais, tais como propósitos comunicativos e modalização. Outra questão semântica tratada refere-se à escalaridade do grau. $\mathrm{O}$ autor expõe um quadro por meio do qual apresenta o escalonamento do grau, que vai do nível máximo, passando pelo enfático e atenuante, entre outros, até a ausência de gradualidade. Em outra subseção, Silva trata da base comparativa do grau, mostrando que a gradualidade é fundamentada na comparação, podendo esta vir explícita ou não. Essa perspectiva, conforme pontua o autor, implica o abandono da distinção tradicional entre grau comparativo e superlativo, de modo que é preferível falar em comparação explícita e comparação implícita.

Ainda no mesmo capítulo, Silva aborda aspectos cognitivos implicados na atribuição de grau, notadamente relacionados a transferências conceituais de domínios ancorados na experiência física/objetiva para o domínio de conteúdos mais abstratos e subjetivos. Essas transferências conceituais se dão por processos metafóricos e metonímicos, sendo arrolados alguns casos. O primeiro deles é a metáfora de quantidade como recurso graduador, fundada no esquema cognitivo INTENSIDADE É QUANTIDADE, em que a noção de um domínio de base mais concreta - a quantidade - é mapeada em outro mais abstrato - a intensidade (cotejem-se muita gente e garota muito bonita). O segundo, a noção gradual derivada do conceito de tamanho/dimensão, envolve, primeiramente, uma operação metonímica, decorrente da relação causa-efeito entre quantidade e dimensão física, seguindo-se daí a ideia de intensificação por meio do mapeamento metafórico entre a noção 
de tamanho e o conceito de intensidade, calcada no esquema INTENSIDADE É TAMANHO/DIMENSÃO (vejam-se bobão, bonitinho, fracote). Outro caso é a conceitualização de peso/força extensiva à noção de intensidade, que também se dá por relação de contiguidade (no caso, associação entre a dimensão física dos seres ou coisas e o peso a eles relacionado ou a força por eles exercida/demandada) e de consequente projeção metafórica, em que o conceito intensivo é mapeado em termos do que é pesado, forte, poderoso etc. (confiram-se sono pesado; chuva forte). Em continuidade, é discutida a ideia de grau oriunda do conceito de localização, com base na associação entre os esquemas cognitivo-perceptuais mais elementares de recipiente (ou contêiner) e de quantidade mensurável, de forma que a noção de intensidade é construída a partir da ideia de limite de localização (vertical ou horizontal) excedido, conforme ilustram profundamente lamentável e juros estratosféricos, por exemplo. $\mathrm{O}$ penúltimo caso é o de metaforizações de grau procedentes de experiências biofísicas e afetivas, relacionadas a conceitos que designam sensações/experiências biológico-corporais (calor, surdez, arrepio, cansaço etc.) e de caráter emotivo/sentimental (medo, temor, paixão etc.), resultando na criação de intensificadores do tipo morrendo de raiva e escorrer de forma assustadora. Nesses casos, a extensão metafórica também deriva de uma associação metonímica mais básica, a de causa-efeito. $\mathrm{O}$ esquema cognitivo seria expresso, conforme sugestão do autor, como INTENSIDADE É EXPERIÊNCIA FÍSICO-EMOTIVA IMPACTANTE. Por fim, é mostrado o conceito gradual por meio de metáforas novas, caso que inclui mapeamentos conceituais situacionalmente construídos. Caracteriza-se pelo uso de noções emergentes, que implicam certo ineditismo e maior nível de elaboração conceitual das metáforas utilizadas. Cabe destacar que as projeções metafóricas e metonímicas discutidas no capítulo são associadas, pelo autor, aos meios de expressão das noções graduadas, de modo que é apresentada farta ilustração da atuação desses processos cognitivos, com exemplares de recursos de codificação variados.

A subseção "A perspectivização do grau" trata do modo como o grau é conceitualizado e focalizado. Segundo o autor, a atribuição de grau está estreitamente relacionada à perspectiva adotada (subjetiva ou convencionalizada socioculturalmente) e à maneira como se conceitualiza e se enfoca um dado fenômeno 
ou situação. Nessa direção, Silva propõe uma caracterização refinada do grau quanto à sua focalização, em termos de aspecto, escalaridade, escopo, explicitude e ancoragem. Quanto ao aspecto, o grau pode ser focalizado como pontual (o que é graduado é exposto como dado e definido) ou processual (o grau é mostrado como em andamento ou com certa duração). Em relação à escalaridade, o grau pode ser perspectivizado como polarizado (estando em um dos extremos da escala) ou escalonado (situando-se em ponto indefinido da escala). Em termos de explicitude, o grau pode ser focalizado de modo direto (o conceito graduado é (ex)posto na superfície textual) ou indireto (o objeto da graduação não está verbalmente explicitado). Com respeito ao escopo, o grau pode ser localizado (a noção graduada incide sobre um dado conceito individualizado de modo mais específico) ou sequencial (a atribuição de grau irradia-se ao longo de um dado segmento textual). Quanto à ancoragem, o grau pode ser focalizado sob o viés objetivo (calcado na experiência com o mundo físico/ material), subjetivo (fundamentado no ponto de vista do falante, no modo como ele deseja comunicar dado conteúdo) ou intersubjetivo (associado à esfera interacional, em que há envolvimento dos parceiros da comunicação).

Na última seção do terceiro capítulo, é abordado o papel do grau na informatividade e na progressão discursiva. $\mathrm{O}$ autor expõe que o grau pode contribuir para a constituição da cadeia informativa do texto, por meio do estabelecimento de nexos coesivos e, dessa forma, auxiliar na continuidade temática e na coerência textual. Sendo assim, pontua o autor, a graduação de um determinado conteúdo pode ser crucial para o acionamento de um tópico temático e para a construção de uma rede de sentidos no processamento discursivo.

O quarto e último capítulo é dedicado aos aspectos formais do grau. Nele são apresentados e caracterizados os recursos linguísticos mais recorrentes de codificação dessa categoria. Além disso, são contemplados a relação função-forma na expressão do grau, conteúdos lexicais vinculados à noção gradual, nível de integração de afixos graduadores e especificidades de registro de formas graduadoras.

Quanto às formas mais comuns de codificação do grau, o autor as organiza conforme o plano da expressão: fonético, morfológico, lexical, sintático e textual. No plano fonético, dá- 
-se por meio do alongamento ou do reforço silábico (enoooorme talento) e da chamada fala silabada (GA-TÉ-SI-MO). No plano morfológico, realiza-se pela afixação (prefixal e/ou sufixal) marcadora da noção de grau (tricedo, belíssima). Quanto ao plano lexical, o grau se mostra no próprio lexema, ou seja, o item lexical em si já denota graduação (pavor, lindo, implorar). No que diz respeito ao plano sintático, o grau revela-se mediante determinados arranjos sintagmáticos ou certas construções oracionais (super mal, o mais longe que pude). Em relação ao plano textual, a noção graduada ocorre de forma distribuída em um dado segmento textual, estando, pois, sinalizada de modo indireto e implícito. $\mathrm{O}$ autor apresenta duas formas: a reiteração, em que o grau é demonstrado por meio da repetição enfática da mesma ideia ao longo de uma sequência do texto; e a gradação discursiva, a qual se processa ao longo (de uma porção) do texto, de modo crescente (gradação aumentativa) ou decrescente (gradação diminutiva).

Também são apresentados casos em que diferentes planos de expressão se fundem. Trata-se da coocorrência superposta de formas diversificadas de codificação do grau pertencentes a planos linguísticos distintos. Segundo destaca Silva, esse procedimento confere à expressão graduadora maior saliência de conteúdo e mais relevância discursiva. É o que se dá, por exemplo, com situações como vai ser um HOrror (lexical e fonético), bem cedinho (morfológico e sintático) e muuuuuito bem (fonético e sintático).

Na seção "A iconicidade na expressão do grau", o autor mostra a relação função-forma na expressão do grau com base nos subprincípios icônicos de quantidade e de integração (proximidade). Em relação ao primeiro subprincípio, conforme expõe Silva, ao acréscimo nocional a um dado conteúdo decorrente da atribuição de grau corresponde um aumento na forma de codificação. Quanto à integração, é mostrado que esse subprincípio evidencia-se, majoritariamente, nas codificações de caráter morfológico e sintático, de sorte que morfemas graduadores encontram-se com maior aderência formal aos elementos por eles modificados, refletindo, assim, a maior proximidade no plano do conteúdo.

Em “Conteúdos lexicais vinculados à noção gradual”, são expostas as classes lexicais a cujo conteúdo normalmente é aplicada a noção gradual. São as que expressam um elemento 
referencial (substantivo), ou uma propriedade (adjetivo, locução nominal), ou um evento/uma ação (verbo), ou uma circunstância (advérbio). Já a seção "Nível de integração de afixos graduadores" trata da gradiência que se pode observar no nível de ligação do afixo à base lexical a que se vincula. Nessa direção, há casos em que o afixo exibe maior aderência morfológica, de modo a serem vistos como um todo inseparável, o que implica perda de analisabilidade (hipertenso); em outros casos, porém, essa ligação se mostra mais frouxa (hipercansado).

Na última seção do capítulo, Silva pontua que existem formas graduadoras mais características de um grupo social, as quais revelam um modo particular de expressão de um segmento social específico, demonstrando diferenças de região, de gênero, de faixa etária, entre outras, como se dá em tricedo (típico de gaúchos) e chiquésima e ar-ra-san-do (mais comum para gays e travestis).

O propósito de examinar o grau em suas diferentes formas de expressão e em diversas situações da língua em uso é cumprido a contento. O autor mostra que o grau é um fenômeno conceitual-discursivo fundado, em primeira instância, na experiência com o mundo físico e social, integrando cognição, língua, cultura e interação. Silva discute, de forma pormenorizada e em linguagem acessível, questões relacionadas aos variados meios de codificação da noção gradual, a aspectos cognitivos da conceitualização e a funções semânticas, discursivas e sociopragmáticas da categoria em foco. A obra permite ao leitor uma ampla visão sobre o tema de que ela se ocupa, além de abrir possibilidades de abordagem dessa temática tanto para a investigação científica quanto para o tratamento em sala de aula, tendo sido este último aspecto o foco da seção "Desdobramentos do tema", ao final do livro. 